DOI: 10.7819/rbgn.v16i51.1488

Área Temática: Marketing

\title{
Fatores que Afetam a Satisfação em Transações Financeiras Online. um estudo sobre o investidor de corretoras de valores mobiliários virtuais
}

\author{
Factors Affecting Satisfaction in Online Financial Transactions: a study of \\ Brazilian home brokers
}

Factores que influyen en la satisfacción de las transacciones financieras por
internet: un estudio sobre inversores de agencias inmobiliarias virtuales

\author{
Jorge Brantes Ferreira ${ }^{1}$ \\ Angilberto Sabino de Freitas ${ }^{2}$ \\ Deborah Coutinho Gil Nunes ${ }^{3}$ \\ Cristiane Junqueira Giovannini ${ }^{4}$
}

Recebido em 28 de novembro de 2012 / Aprovado em 30 de junho de 2014

Editor Responsável: João Maurício Gama Boaventura, Dr.

Processo de avaliação: Double Blind Review

\section{RESUMO}

Este trabalho tem como objeto de estudo a percepção de consumidores com relação a serviços online de corretoras de valores (home brokers). Com base no modelo proposto por Balasubramanian, Konana e Menon (2003), foram analisados os efeitos que diversos construtos relevantes para o consumo de serviços financeiros online (confiança, competência operacional, disposição para a confiança e segurança ambiental percebida) possuem sobre a satisfação dos consumidores ao utilizarem serviços de home broker. Foi elaborado um questionário com escalas existentes na literatura para medir os construtos propostos e analisadas suas relaçóes no contexto brasileiro via equaçôes estruturais. Os resultados apontam forte relação entre a segurança e a competência operacional percebidas, indicando também que a confiança

1. Doutor em Administração de Empresas pela Universidade Federal do Rio de Janeiro (UFRJ). Professor Assistente e Pesquisador do Programa de Pós-Graduação em Administração da Pontifícia Universidade Católica do Rio de Janeiro (PUC-Rio). [jorgebf@gmail.com]

2. Doutor em Administração de Empresas pela Pontifícia Universidade Católica do Rio de Janeiro (PUC-Rio).Pesquisador e Professor adjunto do Programa de Pós-Graduação em Administração da Universidade do Grande Rio (Unigranrio). [angilberto.freitas@gmail.com]

3. Doutora em Administração de Empresas pela Pontifícia Universidade Católica do Rio de Janeiro (PUC-Rio). [debbynunes@hotmail.com]

4. Mestre em Administração de Empresas pela Pontifícia Universidade Católica do Rio de Janeiro (PUC-Rio). [mestrekis@gmail.com]

Endereço dos autores: Pontifícia Universidade Católica do Rio de Janeiro - Rua Marquês de São Vicente, 225, Gávea, Cep. 22451-900- Rio de Janeiro - Brasil 
impacta significativamente o grau de satisfação de consumidores brasileiros quando utilizam serviços financeiros online.

Palavras chave: Home broker. Confiança. Satisfação. Investidor online. Serviços financeiros.

\section{ABSTRACT}

This paper evaluated consumers' perceptions of Brazilian Home Broker services in the online environment. Based on the model suggested by Balasubramanian, Konana and Menon (2003), the effects of relevant online consumer behavior constructs on customer satisfaction with the service were analyzed. Constructs such as perceived operational competence, willingness to trust and perceived environmental security were employed, in a model fully mediated by trust. A questionnaire with scales previously used in literature was employed to measure the relevant constructs and structural equations applied to analyze the relationships found. Results show a strong relationship between perceived environment security and perceived operational competence, indicating that trust formation precedes satisfaction in online financial services transactions within the Brazilian context.

Keywords: Home broker. Trust. Satisfaction. Online investor. Financial services.

\section{RESUMEN}

Este trabajo tiene como objetivo estudiar la percepción de los consumidores sobre los servicios de Agencias Inmobiliarias online (home brokers). Con base en el modelo propuesto por Balasubramanian et al. (2003), se analizaron los efectos que varias variables relacionadas con el uso de servicios financieros online (confianza, competencia operativa, la disposición a confiar y la percepción de seguridad ambiental) tienen sobre la satisfacción del consumidor al utilizar servicios de home broker. Se elaboró un cuestionario con escalas existentes en la literatura para medir los constructos propuestos y sus relaciones se analizaron en el contexto brasileño a través de ecuaciones estructurales. Los resultados muestran una fuerte relación entre la percepción de seguridad y la percepción de la competencia operativa, indicando además que la confianza influye significativamente en la satisfacción de los consumidores brasileños cuando utilizan servicios financieros online.

Palabras clave: Agencia Inmobiliaria. Confianza. Satisfacción. Inversores online. Servicios financieros.

\section{INTRODUÇÃO}

No Brasil, o mercado de corretoras de valores mobiliários tem passado por uma série de mudanças nos últimos anos. A estabilização da economia, o desenvolvimento de tecnologias de comunicação e informação e a entrada de players internacionais, entre outros fatores, têm contribuído para profissionalizar as empresas do setor, tornando esse mercado cada vez mais concorrido e eficiente e aproximando-o da maturidade. Acompanhando essas mudanças, os consumidores também estão evoluindo, tornando-se cada vez mais exigentes. $\mathrm{O}$ resultado dessas transformaçóes é uma geração de consumidores mais experientes, bem informados e críticos, que esperam cada vez mais dos bens e serviços que utilizam.

Um dos aspectos que mais chamam a atenção nessas mudanças é a migração de investidores para o ambiente virtual. Com o aumento de corretoras online, chamadas de home brokers, o acesso ao mercado de ações se tornou mais simples, principalmente para o pequeno investidor pessoa física. O grande sucesso desse sistema se reflete em um número cada vez maior de usuários do serviço. Verifica-se que o número de investidores online faça-você-mesmo tem crescido em um ritmo notável desde que a primeira corretora eletrônica abriu as suas portas virtuais em 1994 (KONANA, MENON, BALASUBRAMANIAN, 2000). No Brasil, o sistema home broker foi implantado em março de 1999 pela Bovespa e é semelhante aos serviços de home banking oferecidos pela rede bancária. 
Nesse tipo de relacionamento de longo prazo, como no caso da relação com os home brokers, é necessário, entretanto, que o consumidor se sinta satisfeito (MORGAN, HUNT, 1994). Um cliente insatisfeito geralmente procura substituir o fornecedor por outra alternativa, se estiver disponível, principalmente em ambientes em que os custos de mudanças sáo baixos (SANTOS, FERNANDES, 2008). O inverso também é intuitivo: clientes satisfeitos são geralmente mais inclinados a permanecer no relacionamento (PEPPERS, ROGERS, 2010).

Embora se aceite que existe uma relaçâo positiva entre a satisfaçáo dos clientes e sua fidelização, a relação entre a satisfação do cliente e a duração da relação é mais complexa. É preciso entender, então, que fatores afetam essa satisfação para garantir que ela seja mantida em níveis satisfatórios para que o cliente continue a transacionar com a empresa. Em ambientes de investimento online, aspectos como segurança e competência operacional são fatores que podem influenciar a satisfação final do cliente (BALASUBRAMANIAN, KONANA, MENON, 2003). Harrison (2003) identificou que, em serviços financeiros, a confiança é um dos aspectos mais importantes. Morgan e Hunt (1994) argumentam que, ao ganhar a confiança dos usuários, as empresas têm maior chance de aumentar o comprometimento deles com a empresa, o que elevaria a chance de retê-los para os próximos negócios, aumentando, assim, o valor do cliente ao longo do relacionamento (PEPPERS, ROGERS, 2010).

Segundo Parasuraman, Zeithaml e Berry (1988), em ambientes tradicionais, confiança e garantias são normalmente geradas por observaçóes dos consumidores em relação ao conhecimento dos funcionários e responsabilidade; os consumidores avaliam a confiança separadamente de outras dimensôes de qualidade de serviços. Contudo, nos ambientes online, com a ausência de interação entre os indivíduos, a confiança cresce à medida que os serviços são utilizados repetidamente, levando a uma interação cada vez maior do cliente com o prestador de serviço (BALASUBRAMANIAN, KONANA, MENON, 2003). Essas interaçóes ajudam o cliente a ter percepçóes mais precisas sobre as características dos serviços, tais como confiança da informação, disponibilidade do website e eficiência na execução das transaçôes.

Para que se obtenha a confiança do consumidor, é preciso, no entanto, também compreender como ela é formada. Nesse sentido, aspectos como a dimensáo segurança tem papel crucial em sua construção. Kim et al. (2010) propóem um modelo conceitual que delineia os determinantes tanto da segurança percebida quanto da confiança percebida pelos consumidores na utilizaçáo de sistemas de pagamento eletrônico. Já Kim, Chung e Lee (2011) apontam que a segurança percebida tem um efeito significativamente positivo sobre a confiança, ao passo que Balasubramanian, Konana e Menon (2003) sugerem que os clientes valorizam a segurança fornecida por instituiçóes reguladoras e isso afeta diretamente a confiança que possuem em um ambiente de investimento virtual. Assim, pode-se inferir que um ambiente fortemente regulamentado, em que o órgão regulador é atuante, contribui para maior segurança dos players de mercado, e com isso gera maior confiança por parte dos usuários de sistemas online de home broker. No Brasil, o mercado de capitais em que as corretoras estão inseridas é altamente regulado, com intensa atuação de órgãos como a Comissão de Valores Mobiliários (CVM) e a Bolsa de Valores de São Paulo (Bovespa), o que poderia justificar uma sensação de segurança percebida pelos investidores, facilitando, assim, a decisão de compra do investidor no ambiente virtual.

Diante do aumento da importância desse serviço para o setor financeiro no Brasil e por haver uma lacuna de estudos sobre esse tema no contexto brasileiro, partiu-se da seguinte questão de pesquisa: Que fatores influenciam a satisfação do investidor no processo de transação no ambiente de uma corretora de valores mobiliários virtual? tendo como objetivo avaliar o efeito que diversos construtos relevantes para o consumo de serviços financeiros online possuem sobre a satisfação dos consumidores ao utilizarem serviços de home broker. Com base em uma adaptação do estudo de Balasubramanian, Konana e Menon (2003), é proposto um modelo empírico para validar a relação entre diversos fatores e a satisfação de 
consumidores com serviços disponibilizados por corretoras de valores brasileiras.

Sendo o foco desse estudo o contexto online de serviço de home broker, e com dados coletados de investidores online brasileiros, foram analisadas as relações entre diversas características dos serviços oferecidos, como segurança e competência operacional, que levam o consumidor a ter confiança no prestador e como essas dimensões afetam a satisfação do consumidor.

\section{REVISÃO DE LITERATURA}

\section{I Ambientes virtuais}

Em razão das mudanças que estão ocorrendo no ambiente competitivo, os paradigmas tradicionais de gestão estratégica vêm sendo questionados sobre sua adequação frente aos novos arranjos organizacionais como os ambientes virtuais (GULATI, NOHRIA, ZAHEER, 2000). Alguns autores chegam a apontar que, pelo fato de a virtualidade permitir integração e simultaneidade de funçôes, há uma explosão ou implosão da cadeia de valor (VENKATRAMAN, HENDERSON, 1998). Outros contestam a ideia de as implicaçóes dessas novas tecnologias de comunicação e informação reverterem em mudanças qualitativas (PORTER, 1999). Dessa forma, ambientes virtuais representam novos desafios gerenciais e estratégicos, trazendo à tona a necessidade da identificação dos fatores críticos para o sucesso da gestão de empresas que operam em redes virtuais.

Uma das principais características dos ambientes virtuais é que não há interação humana direta, e o cliente é "atendido" pela interface online do prestador de serviço. Nesses casos, várias dimensóes convencionais de qualidade, como aparência física das instalaçôes e dos empregados, simpatia e proatividade são pouco ou nada relevantes nesses ambientes (ZEITHAML; PARASURAMAN; MALHOTRA, 2000). Segundo Balasubramanian, Konana e Menon (2003), a interface do sistema e sua eficiência por meio de repetidas interaçôes é que vão dimensionar a satisfação dos consumidores.

Rossi (2003) descreve como elemento mais significativo para os consumidores online a interatividade, afirmando que ela depende da facilidade de navegação e do tempo de resposta do portal a uma solicitação feita pelo usuário. $\mathrm{O}$ autor conclui também que a facilidade de navegar no site, a redução da incerteza na compra e a adaptação do site às características do usuário são elementos críticos para a formação de preferências por sites na Internet. Por fim, mostra que os fatores considerados de extrema relevância para a fidelização do cliente estáo relacionados à confiança (garantia de entrega do bem/serviço; privacidade dos dados pessoais; prazos de entrega confiáveis; confirmação de pedido por e-mail após compra; formas de pagamento seguras) e à conveniência (ferramentas de busca; localização de informaçôes; navegabilidade; facilidade de concretizar uma compra).

Nesse contexto, um dos segmentos que está se apropriando das potencialidades do ambiente virtual é o setor de corretoras de valores mobiliários, os chamados home brokers. Segundo a Comissão de Valores Mobiliários, em seu documento Negociação "online” (CVM, [20--]), o home broker, implantado no Brasil em março de 1999, é um sistema que possibilita ao investidor encaminhar ordens de compra e venda de açôes e de opçôes pela Internet, por meio de corretoras credenciadas pela Bolsa de Valores de São Paulo (Bovespa) para tal fim em um sistema faça-você-mesmo. É um sistema de comunicação que funciona como um canal de relacionamento entre os investidores e as corretoras com o intuito de facilitar e simplificar a atividade de compra e venda de açóes, permitindo que haja maior participação de pessoas físicas no mercado de valores mobiliários. Algumas das vantagens da utilização do home broker são o baixo investimento inicial, acesso a cotaçóes em tempo real, agilidade e rapidez nas ordens, maior transparência e a disposição de análises gratuitas por parte das corretoras (ANDERSEN, 2006). 


\subsection{A satisfação}

A satisfação pode ser descrita como o resultado de uma combinação do nível de expectativa esperada e a desconfirmação (ou confirmação) dessas expectativas ao longo das interaçôes das transaçóes entre o indivíduo o provedor de serviços (OLIVER, 1980).

Severt (2002) define a satisfação como uma condição afetiva do consumidor, resultante de uma avaliação global de todos os aspectos que compóem a relação de consumo. Já Geyskens, Steenkamp e Kumar (1999) apontam que a satisfação pode ser dividida em duas perspectivas diferentes. A primeira perspectiva considera a satisfação como uma predisposição afetiva sustentada pelas condiçôes econômicas, como o volume de vendas ou margens de lucro obtidas. Essa é uma satisfação econômica, uma vez que está relacionada ao desempenho econômico. A segunda perspectiva não leva em consideração o aspecto econômico, considerando fatores mais psicológicos, como o cumprimento pelo parceiro de uma promessa ou a facilidade de relacionamento com o parceiro acima mencionado.

Do ponto de vista transacional, a satisfação vai depender de cada transação ocorrida, mas do ponto de vista relacional, como no caso da relação com corretoras de valores mobiliários, o processo é diferente. Com cada novo intercâmbio consumidor-empresa, a percepção do indivíduo é alimentada por novas informaçôes, que servem de combustível para determinar o nível de satisfação em um determinado momento. Assim, este estudo se concentra na perspectiva psicológica da satisfação. Desse ponto de vista, a satisfação é considerada como uma avaliação global ou uma atitude do consumidor sobre o comportamento da empresa resultante das interaçóes ocorridas entre ambas as partes na relação. Portanto, a satisfação do consumidor não é o resultado de uma operação específica, mas de uma avaliação global da história de relacionamento entre as partes (SHANKAR, SMITH, RANGASWAMY, 2003).

\section{$2 \cdot 3$ A confiança}

Um importante aspecto em relacionamentos de longo prazo é a confiança, e como ela se estabelece na relação entre organização e consumidor. Esse construto tem sido um tema central nos estudos baseados em relacionamentos de longo prazo (SIRDESHMUKH, SINGH, SABOL, 2002; TALEGHANI, CHOOBEH, MOUSAVIAN, 2011), como no caso da relação do objeto de estudo deste trabalho. Morgan e Hunt (1994) apontam que, para manter um relacionamento de longo prazo com uma empresa, o cliente precisa ter sua confiança conquistada e sentir que a organização está comprometida com seus interesses e necessidades, oferecendo-lhe valor superior. Assim, a manutenção do relacionamento é função direta da capacidade da organização em cumprir suas promessas, aspecto que está diretamente relacionado à confiança, que emerge a partir do momento em que uma das partes acredita na outra (MOORMAN, DESHPANDE, ZALTMAN, 1993). A confiança serve, então, como a cola que sustenta o relacionamento entre o cliente e a empresa.

Por ter inúmeros estudos provenientes de diversas áreas do conhecimento, a conceituação do construto confiança acaba gerando variadas definiçôes (SINGH, SIRDESHMUKH, 2000). Para contornar tal situação, Rousseau et al. (1998, p. 395) propuseram uma definição consensual de confiança como "um estado psicológico que compreende a intenção em aceitar uma vulnerabilidade baseada em expectativas positivas das intenções ou comportamentos de outro". Essa definição apresenta duas partes distintas: (1) $\mathrm{Na}$ primeira parte, a confiança é relacionada ao parceiro de trocas, aceitando-se a vulnerabilidade contextual. Essa definição é relacionada à confiança comportamental e refere-se à tendência de ação de uma parte em relação à outra. (2) Na segunda parte, a confiança é relacionada com expectativas (positivas) sobre as intençôes e/ou comportamentos do parceiro de trocas. É focada na crença de uma das partes de que a outra agirá de maneira responsável, evidenciando integridade, e que não será prejudicial à outra parte (ROUSSEAU et al., 1998). Ou seja, o construto é separado em duas dimensões: (1) confiança como um estado psicológico e (2) como uma escolha de comportamento (SIRDESHMUKH, SINGH, SABOL, 2002). 
Por sua vez, Smith e Barclay (1997) apontam dois aspectos dominantes relacionados à confiança: como uma expectativa cognitiva e como um comportamento de tomada de risco. Tais aspectos complementam a ideia de Moorman, Deshpande e Zaltman (1993) de que a confiança envolve vulnerabilidade e incerteza e de que as açóes de confiabilidade de uma das partes aumentam a vulnerabilidade da outra. Para os autores, a incerteza é uma dimensão necessária para a confiança, uma vez que seria desnecessário para a concretização de uma troca confiar em parceiros sobre os quais se tem total conhecimento e controle sobre as açóes.

De forma semelhante, Johnson e Grayson (2005) descrevem que a confiança interpessoal tem dimensôes cognitivas e afetivas. A confiança cognitiva seria baseada na convicção ou conhecimento que um cliente possui sobre a competência e confiabilidade de um prestador de serviços. Já a confiança afetiva seria caracterizada pela segurança percebida e os pontos fortes existente em uma relação de confiança que se coloca com um parceiro com base em sentimentos gerados pelo nível de cuidado e preocupação que ele demonstra. De acordo com Johnson e Grayson (2005), a confiança cognitiva é objetiva, ao passo que a confiança afetiva é um processo subjetivo de avaliação. Além disso, Morrow, Hansen e Pearson (2004) sugerem que a confiança afetiva teria um efeito positivo sobre indicadores náo financeiros de desempenho cognitivo, ao passo que a confiança cognitiva pode ter um efeito positivo no desempenho financeiro.

A seguir são apresentados outros fatores que afetam direta e indiretamente a satisfação em transações no ambiente online, bem como as hipóteses deste estudo.

\subsection{Fatores que afetam a satisfaçáo no compra de serviços de home broker: um modelo para avaliar a satisfaçáo do investidor online}

A construção da satisfação pode ser afetada por diversos fatores (CASALO, FLAVIAN, GUINALIU, 2007; GEYSKENS, STEENKAMP, KUMAR, 1999). Em serviços financeiros, um fator apontado determinante para a satisfação do consumidor é a confiança (HARRISON, 2003).
Uma vez que as empresas de serviços financeiros possuem uma responsabilidade na gestáo dos fundos de seus clientes, a confiança se torna um fator crucial na relação cliente-empresa. Para se compreender como ela é construída, entretanto, é importante apontar outros fatores que influenciam sua construção e sua relação com a satisfação em situaçôes de transaçôes recorrentes, como no caso das transaçóes nos home brokers. A seguir, são descritos os fatores que podem afetar sua construção e apresentam-se as hipóteses do modelo a ser testado.

A partir de relaçóes estabelecidas na literatura, o presente estudo propóe um modelo parcimonioso para a compreensão da formação da confiança e de como ela se relaciona com a satisfação dos investidores com prestadores de serviços de home broker. Com base em uma adaptação do modelo de Balasubramanian, Konana e Menon (2003), são considerados o efeito direto positivo da confiança sobre a satisfação e os efeitos indiretos da segurança, competência operacional e predisposição para confiança do cliente.

$\mathrm{Na}$ adaptação do modelo ao caso brasileiro, não foi levada em consideração a influência do preço, pois, uma vez que, no caso da amostra usada para este estudo, o serviço ocorre de forma recorrente, foi avaliada somente a interação dos clientes com uma mesma corretora. Assim, pode-se inferir que o preço cobrado pelo serviço prestado não é fator relevante para influenciar a satisfação, pois o consumidor, caso estivesse insatisfeito, poderia mudar de corretora, uma vez que os custos de mudança seriam baixos. Esse argumento está em linha com Santos e Fernandes (2008), que identificaram no contexto brasileiro de serviços financeiros e do setor aéreo que os custos de mudança possuem baixa influência nas intençóes de recompra, indicando que a criaçáo de mecanismos que dificultem a saída do cliente não é suficiente para mantê-lo. Assim, o fator preço, nesse caso em particular, pode ser considerado irrelevante para afetar a satisfação do indivíduo, uma vez que pode mudar de corretora sem grandes custos envolvidos.

O modelo proposto (Figura 1), adaptado de Balasubramanian, Konana e Menon (2003), 
postula que a predisposição à confiança afeta direta e positivamente a competência operacional percebida (H1) e a percepção do consumidor com relação à segurança do ambiente de investimentos (H2). Por sua vez, a segurança do ambiente de investimentos afeta positivamente a competência operacional percebida (H3). No que diz respeito à satisfação geral com o prestador de serviço home broker, ela é diretamente influenciada pela confiança (H6) e indiretamente pela competência operacional percebida, que influencia positivamente a confiança (H5), e pela segurança do ambiente de investimentos, que também influencia positivamente a confiança (H4).

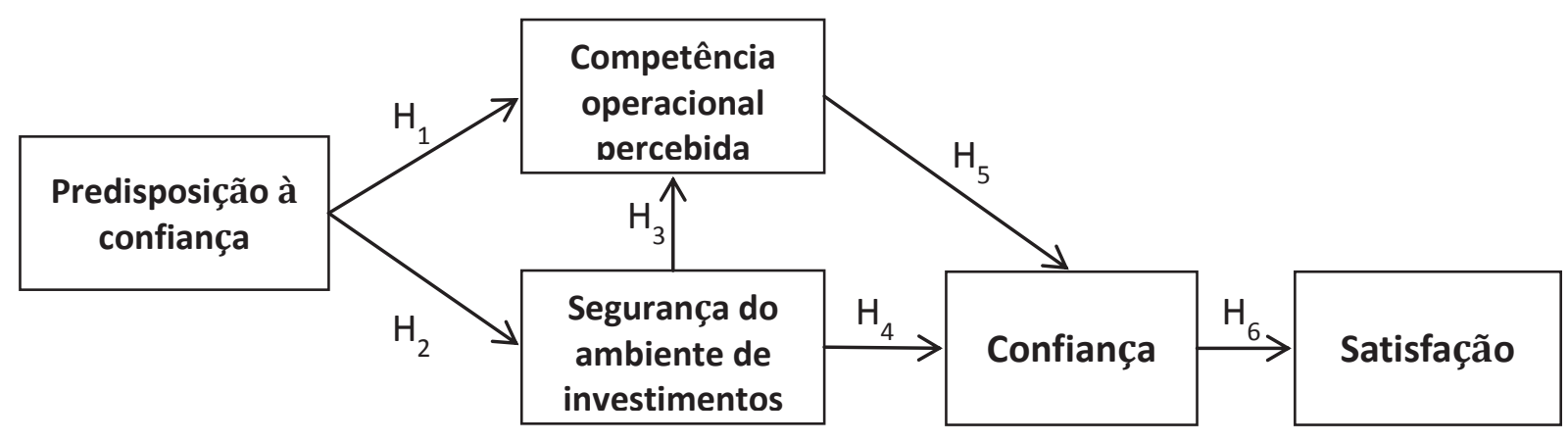

FIGURA 1 - Modelo proposto

Fonte: Adaptado de Balasubramanian, Konana e Menon (2003)

A seguir, discute-se cada constructo e as justificativas de cada relação do modelo.

\subsection{Predisposiçâo à confiança e competência operacional percebida}

Um aspecto pouco compreendido na literatura é a predisposição à confiança. Segundo Balasubramanian, Konana e Menon (2003), a predisposição ou inclinação à confiança é o resultado de traços de personalidade e de pontos de vista do indivíduo, dotando-o de uma tendência geral de confiar em outros. A confiança é uma variável endógena do modelo, pois sua formação no indivíduo depende das açôes da empresa, ao passo que a predisposição à confiança é uma variável externa, pois é uma característica própria de cada indivíduo, sendo, assim, não sujeita à ação gerencial.

Já a competência operacional pode ser definida como a percepção do consumidor a respeito da habilidade de uma empresa virtual em apresentar altos níveis de desempenho operacional no dia a dia (KONANA, MENON, BALASUBRAMANIAN, 2000). Segundo Balasubramanian, Konana e
Menon (2003), as percepçóes de competência operacional são particularmente relevantes quando a confiança é formada por meio de repetidas interaçóes. É fato estabelecido entre pesquisadores de comportamento que indivíduos agem segundo um "viés confirmatório" que os leva a selecionar, interpretar e recordar informaçôes que sejam consistentes com suas atitudes (TAYLOR, BROWN, 1988). Quando algum aspecto é de difícil observação, é comum sua subjetivação. Nesses casos, evidências parecem indicar que crenças preestabelecidas tenham mais valor que a necessidade de escrutínio da realidade (LORD, LEPPER, ROSS, 1979). Uma alta predisposição à confiança pode ajudar a formar atitudes positivas em relação ao objeto de confiança, conduzindo a avaliaçôes mais generosas de competência. Por outro lado, uma baixa vontade em confiar pode levar a avaliaçóes inferiores de desempenho operacional e à supressão dos sinais mais positivos de desempenho (BALASUBRAMANIAN, KONANA, MENON, 2003). Assim, é proposta a primeira hipótese do modelo:

Hipótese 1: A predisposição à confiança de um consumidor terá efeito direto e positivo sobre a competência operacional 
Jorge Brantes Ferreira / Angilberto Sabino de Freitas / Deborah Coutinho Gil Nunes / Cristiane Junqueira Giovannini

percebida por ele em relação ao uso de serviços de home broker.

\subsubsection{Predisposiçâa à confiança e segurança do ambiente percebida}

Investidores que possuam uma predisposição natural para acreditar na honestidade da sociedade em geral provavelmente acreditarão mais na segurança proporcionada por sistemas de controle definidos por instituiçôes regulamentadoras (MCKNIGHT, CUMMINGS, CHERVANY, 1998), como a CVM e a Bovespa. Assim, dentro de um ambiente regulamentado, a segurança do ambiente percebida pode ser conceituada como a percepção do consumidor sobre a segurança em fazer transações com determinada empresa inserida em setores regulamentados institucionalmente ou socialmente (BALASUBRAMANIAN, KONANA, MENON, 2003).

A importância de garantias e estruturas institucionais que regulam atividades econômicas cresce na ausência de relacionamentos pessoais entre os prestadores de serviço e os clientes (SHAPIRO, 1987). Segundo McKnight, Cummings e Chervany (1998), a confiança baseada na estrutura institucional deriva de dois componentes: normalidade situacional e certeza estrutural. $\mathrm{O}$ primeiro representa a crença do indivíduo de que tudo está "certo", ou seja, que aparências, comportamentos e ambiente estão de acordo com o esperado naquela situação, e o segundo advém da imposição por instituiçôes legal e socialmente sancionadas de normas de procedimentos e integridade. Ao criarem regulamentos, garantias e caminhos para recursos legais, essas instituiçóes definem padrôes. No mercado brasileiro, essas instituiçôes são representadas pela CVM, Bovespa e CBLC. No contexto do investimento online, a certeza estrutural é de grande importância, pois permite a monitoraçáo da qualidade dos serviços prestados e a transparência no mercado.

Assim, considerando o ambiente virtual como um canal entre o prestador de serviços e o consumidor, é de esperar que uma maior predisposição a confiar no serviço oferecido afete positivamente a segurança percebida pelo consumidor no sistema. Dessa forma, é proposta a segunda hipótese do modelo:

Hipótese 2: A predisposição à confiança de um consumidor terá um efeito direto e positivo sobre a segurança percebida por ele em relação a serviços de home broker.

\subsubsection{A segurança do ambiente percebida e a competência operacional}

Garantias e estruturas institucionais que regulam atividades podem funcionar no sentido de fornecer diretrizes às organizaçóes sobre como devem atuar (SHAPIRO, 1998), delineando responsabilidades, bem como definindo como devem se comportar em termos operacionais. No Brasil, a CVM tem emitido diversas regras de como as corretoras devem se comportar em termos operacionais com relação à capacidade dos sistemas, escalas, planejamento de contingência (em caso de falha dos sistemas), oportunidade de negócios, qualidade das informações prestadas, fóruns de discussão online e privacidade. Assim, com base nesses argumentos é proposta a hipótese 3 :

Hipótese 3: A segurança do ambiente de investimentos percebida pelo consumidor em relação ao sistema de home broker disponibilizado por uma corretora de valores terá efeito direto e positivo sobre a competência operacional percebida por ele em relação ao uso de serviços de home broker.

\subsubsection{A segurança do ambiente percebida e a confiança}

No ambiente online, a confiança pode ser definida como a aceitação de um estado de risco psicológico pelo usuário de Internet, com base em expectativas positivas das intençôes ou comportamentos do provedor de serviços virtuais, sendo um aspecto crítico para transaçóes online (GEFEN, 2000; YOON, 2002). Já Chiung-Ju e Hui-Ju (2009) definem a confiança no ambiente virtual como a convicçáo que o consumidor possui acerca da confiabilidade, benevolência e integridade do provedor de serviços online. 
Conforme já afirmado, garantias estruturais e institucionais ocorrem quando instituiçōes social ou legalmente sancionadas impóem normas de desempenho e integridade aos agentes econômicos. Tais garantias estruturais aumentam a segurança percebida no ambiente de negociação, refletindo na crença de que instituições reguladoras salvaguardam os interesses dos investidores (BALASUBRAMANIAN, KONANA, MENON, 2003), garantindo uma padronização das transaçôes para o setor. Garantias estruturais são importantes para o ambiente virtual, pois podem monitorar a qualidade do serviço prestado pelas corretoras em nome dos investidores. Além do mais, agências regulatórias agem para garantir maior transparência do setor e podem implementar diretrizes que forcem as empresas a garantir níveis mínimos de segurança (BARBER, ODEAM, 2000). Em paralelo, como o próprio mercado age sobre a segurança, corretoras que não sejam de confiança ou que prestem maus serviços rapidamente se tornam conhecidas do público e correm o risco de serem evitadas. Balasubramanian, Konana e Menon (2003) também afirmam que quando a segurança é percebida como elevada, investidores tendem a depositar mais confiança no corretor, mesmo na ausência de contato pessoal. Nesse contexto, é proposta então a seguinte hipótese:

Hipótese 4: A segurança do ambiente de investimentos percebida pelo consumidor em relação ao sistema de home broker disponibilizado por uma corretora de valores terá efeito direto e positivo sobre a confiança sentida por ele em relação ao uso de serviços de home broker.

\subsubsection{A competência operacional percebida e a confiança}

Ao investigar a confiança de investidores de serviços financeiros online, Shih-Ming, Hsiu-Li e Hui-Min (2012) confirmaram que a confiança no provedor de serviços é fator importante em sua decisão em continuar com a intenção de usar os serviços. Se os clientes confiam no provedor de serviços online e acreditam na confiabilidade e integridade do prestador de serviço, provavelmente irão se sentir mais à vontade quando estiverem fazendo transaçôes e divulgando suas informaçôes pessoais online.

No ambiente online, as percepçôes de competência operacional são particularmente relevantes quando a confiança é formada por meio de repetidas interaçóes (BALASUBRAMANIAN, KONANA, MENON, 2003). Na utilização da ferramenta de home broker, vários fatores são levados em consideração na definição da competência operacional dos serviços oferecidos, como tempo de execução das transaçōes e os preços a elas relacionados, qualidade dos resultados das pesquisas e assistência de qualidade/presteza do atendimento (KONANA, MENON, BALASUBRAMANIAN, 2000). Assim, espera-se que a competência operacional percebida pelo consumidor de uma corretora virtual afete positivamente a confiança sentida por ele em relação a ela.

Ou seja, a relação de confiança é estabelecida por meio da percepção da competência do agente intermediador, responsável pela implementação da estrutura e processos de operação e negociação. Segundo Giffen (1967), três dimensôes influenciam a credibilidade das fontes: (1) perícia ou expertise, que captura a quantidade de informaçóes pertinentes disponíveis; (2) confiança/segurança da origem das informaçôes, que captura consistência; e (3) intenção da fonte para com os interessados. As duas primeiras são relevantes dimensóes para análise de competência operacional de corretoras. Por outro lado, pode-se inferir também que, nesses ambientes, a interface de negociação pode parecer rápida e conveniente, mas não se pode dizer que sejam plenamente conhecidos os processos no segundo plano, como o fluxo das ordens, o descobrimento do preço e a execução de ordens (KONANA, MENON, BALASUBRAMANIAN, 2000). Dessa forma, a percepção de competência operacional pode gerar confiança, em razão da natureza interativa do investidor online. Sendo assim, é proposta a seguinte hipótese: 
Hipótese 5: A competência operacional percebida pelo consumidor com relação ao sistema de home broker disponibilizado por uma corretora de valores terá efeito direto e positivo sobre a confiança sentida por ele em relação ao uso de serviços de home broker.

\subsubsection{Confiança e satisfação}

No ambiente tradicional, a noção de que a satisfação precede a confiança já está bem estabelecida na literatura (GEYSKENS STEENKAMP, KUMAR, 1998; TAM, 2012), pois a confiança é uma avaliação agregada em algum nível superior (SELNES, 1998), ao passo que a satisfação é uma resposta pós-compra imediata que reflete o grau em que um serviço atingiu as expectativas dos clientes. Assim, a satisfaçáo atua como uma fonte de confiança. Uma experiência gratificante vivenciada pelos clientes com um prestador de serviços pode reforçar a confiabilidade e a integridade percebida pelo cliente do fornecedor de serviços (SINGH, SIRDESHMUKH, 2000). Já Singh e Sirdeshmukh (2000) propuseram uma relação circular entre confiança e satisfação. De acordo com esses autores, em uma situação de pré-compra, é necessário que o cliente se sinta confiante para realizar a transação.

De forma análoga, nas transaçôes online, o consumidor precisa ter a confiança antes de efetuar a compra. Entretanto, ao contrário do ambiente offline, pesquisas apontam que no ambiente virtual essa relação ocorre de forma inversa, ou seja, a confiança precede a satisfação, uma vez que desempenha um papel central na decisão de compras do consumidor online, como na compra de livros online (CHIOU, PAM, 2009), leilóes (PO-HUNG, 2013) e ingressos (SIU, ZHANG, LAM, 2010). Johnson, Bardhi e Dunn (2008) apontam que a confiança na tecnologia antecede a satisfaçáo do consumidor no ambiente online.

Assim, a satisfação do cliente só pode ser alcançada quando os clientes se sentem confortáveis em realizar pedidos por meio da Internet, e isso só ocorre quando o consumidor possui confiança no provedor de serviços. Outros estudos reforçam essa tese, como a pesquisa de Harris e Goode (2004), que identificaram essa ligação positiva direta da confiança precedendo a satisfação. Entretanto, essa relação ainda não está clara. Taleghani, Choobeh e Mousavian (2011) identificaram que, em sites de vendas de serviços turísticos, a satisfação precede a confiança. Segundo eles, embora seja possível o cliente não confiar em compras online, açôes que estimulem a satisfação do consumidor durante o processo de compra podem garantir a decisão de compra mesmo com o consumidor não tendo plena confiança no fornecedor do serviço. Essa constatação pode estar associada ao grau de relacionamento com o provedor e o tipo de serviço ofertado.

Liang e Wang (2005) sugerem que a satisfação por si só não pode garantir o comportamento de recompra do consumidor. Segundo eles, apenas quando os consumidores passam a ter confiança em um provedor de serviços online é que eles mostram comportamento de compra recorrente. Assim, no ambiente virtual, a confiança torna-se um fator ainda mais crítico (WANG, EMURIAN, 2005), pois, ao contrário das lojas de varejo offline, a incapacidade de interagir com um vendedor e com as mercadorias e o alto grau de intangibilidade do ambiente virtual contribuem para aumentar a percepção de risco dos consumidores acerca das transaçôes online. Consequentemente, a confiança pode se constituir um aspecto-chave para facilitar a decisão de compra pela Internet (ROMAN, 2007).

Ao tentar identificar os papéis de satisfação e confiança e suas consequências em trocas relacionais, Garbarino e Johnson (1999) concluíram que diferentes fatores medeiam as intençóes futuras de clientes com fracos e fortes relacionamentos com as empresas (também denominados clientes transacionais e relacionais). A primeira importante conclusão é a de que a satisfação geral determina as intenções futuras de clientes com pouco relacionamento com a empresa. Já para os clientes relacionais, os grandes responsáveis pelas intençôes futuras são a confiança e o comprometimento. Assim, programas de marketing transacionais baseados na gestão da satisfação seriam mais efetivos para clientes com pouco relacionamento, ao passo que programas de marketing de relacionamento 
voltados para clientes relacionais deveriam ter como foco a construção e manutenção da confiança e do comprometimento, e não da satisfação (GARBARINO, JOHNSON, 1999).

Como a competência operacional e a segurança do ambiente dizem respeito a aspectos de percepção do consumidor sobre o sistema utilizado, levando-o a utilizar (ou não) o sistema e a criar (ou não) uma relação com a empresa que fornece o serviço, optou-se pelo teste de um modelo no qual a confiança serve como mediadora entre as variáveis relacionadas ao sistema e a satisfação (uma vez que sem confiança e sem utilizar o sistema o consumidor não haveria como gerar percepções de satisfação). Com base nessa argumentação, no caso de trocas relacionais, a relação entre confiança e satisfação em ambientes virtuais permite propor a seguinte hipótese:

Hipótese 6: A confiança do consumidor a respeito do sistema de home broker disponibilizado por uma corretora de valores terá efeito direto e positivo sobre a satisfação sentida por ele em relação ao uso de serviços de home broker.

\section{METODOLOGIA}

Com o objetivo de realizar o teste das hipóteses formuladas para o estudo, foi realizada uma cross-sectional survey (PARASURAMAN, GREWAL, KRISHNAN, 2006) com uma amostra não probabilística da população de interesse. Questionários estruturados foram apresentados a consumidores de serviços de home broker em um único momento no tempo.

\section{I Operacionalização das variáveis}

O presente estudo faz uso de escalas já elaboradas e testadas na literatura para a medição de todos os construtos envolvidos na estrutura do modelo proposto. Sendo assim, foram utilizadas as seguintes escalas, sugeridas e testadas por Balasubramanian, Konana e Menon (2003):

- Satisfação: composta por 2 itens;
- Disposição para Confiança: composta por 2 itens;

- Competência Operacional Percebida: composta por 6 itens;

- Confiança Percebida: composta por 4 itens;

- Segurança Percebida: composta por 7 itens.

Os itens incluídos no instrumento de pesquisa foram traduzidos para o português por profissionais, com etapas de tradução e retradução, sendo empregadas para garantir que as escalas em português se aproximassem ao máximo das originais.

Foi realizado um pré-teste do questionário com uma pequena amostra da população de interesse para avaliar a compreensão dos respondentes sobre essa primeira versão. Os resultados obtidos com esse pré-teste inicial serviram para refinar o questionário e elaborar uma nova versão. Essa segunda versão ainda passou por um pré-teste final, em que foi verificado se algum último ajuste era necessário tanto na tradução quanto na apresentação do questionário. Com os resultados deste último pré-teste, foi elaborado o instrumento de pesquisa final, com um total de 21 itens medidos por meio de escalas Likert de cinco pontos, além de sete itens relativos às variáveis demográficas.

\subsection{Amostra e procedimentos de coleta de dados}

A população estudada foi a de usuários de serviços de corretagem online (somente pessoas físicas). Desse modo, a pesquisa só mediu as percepções de investidores que já faziam uso de serviços de home broker e, portanto, poderiam responder sobre suas reais percepçôes de sistemas dessa natureza.

Todos os questionários foram autoadministrados, com um link para o website que continha a pesquisa, tendo sido enviado por e-mail para a lista de clientes disponível. O link para o instrumento de pesquisa foi enviado para 7800 clientes ativos de diversas grandes corretoras brasileiras. A lista foi obtida do banco de dados de um site especializado em investimentos. $\mathrm{Na}$ amostra final foram considerados apenas investidores 
de uma única corretora (a mesma responsável pelo site de investimentos que originou a lista de e-mails) e que haviam utilizado o mesmo sistema de home broker pelo menos uma vez nos últimos seis meses.

Foi obtida uma amostra com 298 questionários (taxa de resposta de 3,82\%), sendo eliminados 43 por ausência de dados e erros de preenchimento. Dessa forma, a amostra final foi composta por 255 questionários válidos (3,27\%). Desses, $35,3 \%$ eram do sexo feminino e $64,7 \%$ do sexo masculino. Em relação ao estado civil, a maioria dos respondentes $(40,8 \%)$ era formada por casados e $23,5 \%$ por solteiros. No que diz respeito à renda familiar média, $38,8 \%$ dos participantes indicaram renda familiar mensal superior a R\$ 10 mil, 26,7\% apontaram renda familiar entre R \$ 5 mil e R \$ 10 mil, 21,5\% entre R \$ 3,5 mil e R \$ 5,5 mil e, por fim, 13\% dos respondentes indicaram renda familiar inferior a $\mathrm{R} \$ 3,5 \mathrm{mil}$. A média de idade observada foi de 41,85 anos, com desvio padrão de 13,97 e intervalo de confiança de $95 \%$ entre 40,13 e 43,58. O volume médio de recursos transacionados pelos respondentes por meio do sistema de home broker avaliado foi de R $\$$ 177.351,90, com desvio padrão de R $\$ 27.419,35$. A soma total de recursos investidos pelos clientes pesquisados até o momento da pesquisa passava dos R \$ 45 milhóes.

\section{RESULTADOS}

\section{I Teste para variância comum de método}

Uma vez que tanto as variáveis dependentes quanto independentes coletadas via instrumento de pesquisa resultaram de opinióes coletadas dos mesmos informantes, os dados estavam sujeitos a problemas de variância comum de método. Seguindo a sugestáo de Podsakoff e Organ (1986), o teste de um fator de Harman foi empregado para examinar até que ponto esse tipo de viés estaria presente nos dados. Os resultados de uma análise de componentes principais sobre todos os itens mensurados indicaram a presença de cinco fatores com autovalor maior do que um, com nenhum fator sendo responsável por quase toda a variância explicada (o fator que explicou mais variância capturou somente $30 \%$ da variância total). Dado esse resultado, conforme indicado por Podsakoff e Organ (1986), os dados não aparentam apresentar problemas de variância comum de método no caso analisado.

\subsection{Modelo de mensuraçáo}

Para testar a validade, unidimensionalidade e confiabilidade das escalas utilizadas no modelo de mensuração efetuou-se uma análise fatorial confirmatória (CFA). Uma análise da matriz de covariância dos resíduos padronizados da CFA indicou diversos itens que estavam contribuindo para o ajuste fraco do modelo. De acordo com esses resultados, o modelo foi ajustado e refinado com a eliminação de três itens pertencentes à escala de competência, um item da escala de confiança e um item da escala de segurança. $\mathrm{O}$ modelo de mensuração final, com 16 indicadores, apresentou bons índices de ajuste (RMSEA = 0,048 com C.I. de 0,032 até 0,062 ; CFI $=0,97$; $\mathrm{IFI}=0,97 ; \mathrm{TLI}=0,96 ; \chi^{2}=148,00$, d.f. $=94$, $\mathrm{p}<0,001, \chi 2 /$ d.f. $=1,57)$.

A validade de face para todas as escalas utilizadas foi garantida durante o desenvolvimento do instrumento de pesquisa (escolha de escalas já utilizadas na literatura, tradução criteriosa e pré-testes). Para verificar a validade nomológica, foi analisada a matriz de correlação entre construtos, com todas as correlações sendo significativas e estando na direção esperada (anexo 1). No que diz respeito à validade convergente, foi calculada a variância extraída média para cada construto (AVE). Todos os valores de AVE calculados estavam entre 0,55 e 0,87 , evidenciando a validade convergente das escalas utilizadas. Com relação à consistência interna e a confiabilidade das escalas utilizadas, todas as escalas atenderam aos níveis mínimos de confiabilidade indicados pela literatura (Fornell, Larcker, 1981), apresentando valores entre 0,73 e 0,93 para o coeficiente alfa e entre 0,70 e 0,89 para a confiabilidade composta. Por fim, todas as variâncias compartilhadas foram inferiores à variância extraída pelos itens que medem os construtos, indicando validade discriminante adequada. 


\subsection{Modelo estrutural}

Uma vez validadas as escalas e os construtos utilizados, procedeu-se com a estimação do modelo estrutural para testar as hipóteses da pesquisa. Todos os índices indicaram um bom ajuste do modelo aos dados. A razão $\chi 2 /$ d.f. foi de 1,58 , sendo, portanto, inferior ao valor máximo de 3,0 sugerido por Byrne (2010). Além disso, os índices de ajuste incrementais se mostraram acima do valor mínimo de 0,90, com CFI de 0,97, TLI de 0,96 e IFI de 0,97. Por sua vez, os índices de ajuste absoluto apresentaram valores abaixo do limite máximo de 0,08 estabelecido pela literatura (HU, BENTLER, 1999; BYRNE, 2010; HAIR et al., 2009), indicando também um bom ajuste do modelo. O RMSEA foi de 0,048 (C. I. de 0,033 a 0,062) e o SRMR foi de 0,039. Dados os índices apresentados, conclui-se que o ajuste do modelo proposto é satisfatório.

Com a verificação do ajuste dos modelos de mensuração e estrutural propostos, foram avaliados os coeficientes estimados para as relaçóes causais entre os construtos (Tabela 1). A verificação de cada uma das hipóteses da pesquisa foi realizada com a análise da magnitude, direção e significância dos coeficientes padronizados, estimados por meio do modelo estrutural (BYRNE, 2010). A figura 2 ilustra as magnitudes e significâncias das relaçôes encontradas.

TABELA 1 - Coeficientes padronizados estimados, hipóteses e significâncias

\begin{tabular}{lccc}
\hline Relação proposta & $\begin{array}{c}\text { Coeficiente } \\
\text { padronizado }\end{array}$ & Sig. & $\begin{array}{c}\text { Hipótese } \\
\text { verificada }\end{array}$ \\
\hline $\mathrm{H}_{1}:$ Disposição $\rightarrow$ Competência & 0,11 & 0,135 & não \\
$\mathrm{H}_{2}:$ Disposição $\rightarrow$ Segurança & 0,20 & 0,030 & sim \\
$\mathrm{H}_{3}:$ Segurança $\rightarrow$ Competência & 0,87 & $<0,001$ & sim \\
$\mathrm{H}_{4}:$ Segurança $\rightarrow$ Confiança & 0,54 & 0,005 & $\operatorname{sim}$ \\
$\mathrm{H}_{5}:$ Competência $\rightarrow$ Confiança & 0,48 & 0,023 & $\operatorname{sim}$ \\
$\mathrm{H}_{6}:$ Confiança $\rightarrow$ Satisfação & 0,89 & $<0,001$ & sim \\
\hline
\end{tabular}

Fonte: Elaborado pelo autor

De acordo com a análise efetuada, o modelo foi capaz de explicar aproximadamente $98 \%$ da variância observada na confiança de consumidores com relação ao uso de serviços de home broker, indicando que o construto pode ser bem explicado pelas variáveis utilizadas. $\mathrm{O}$ mesmo pode ser dito da satisfação de investidores com este tipo de serviço.
Com uma proporção da variância explicada de 79\%, nota-se que o modelo proposto capturou boa parte da variabilidade de tal satisfação. Por sua vez, a competência operacional percebida teve $55 \%$ de sua variância explicada, ao passo que a segurança do ambiente de investimentos teve somente $15 \%$.

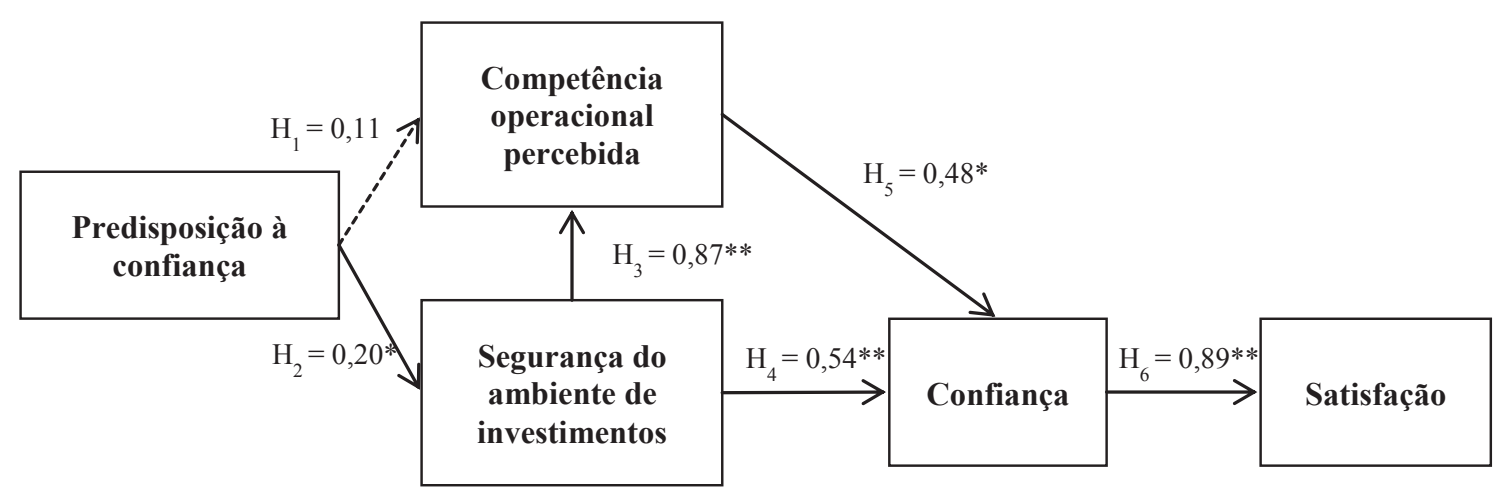

FIGURA 2 - Modelo e relaçôes encontradas (* indica $\mathrm{p}<0,05$; ** indica $\mathrm{p}<0,001$ )

Fonte: Elaborado pelo autor 


\subsection{Discussão dos resultados}

De todas as hipóteses propostas, apenas H1 náo foi suportada, contrariando os resultados de Balasubramanian, Konana e Menon (2003). As outras cinco hipóteses foram todas confirmadas. Discutem-se primeiramente as hipóteses confirmadas. Ao final desta seção, busca-se argumentação sobre a rejeição de $\mathrm{H} 1$

O impacto da disposição para confiança sobre a segurança percebida foi significativo $(p$-value $=0,030)$, confirmando a hipótese 2 de que a disposição para confiança afeta positiva e diretamente a segurança percebida. Esse resultado se alinha à argumentaçáo da literatura que prediz que indivíduos que possuam uma predisposição natural para acreditar na honestidade da sociedade em geral provavelmente acreditarão mais na segurança proporcionada por sistemas de controle definidos por instituiçóes regulamentadoras (MCKNIGHT, CUMMINGS, CHERVANY, 1998). No caso da relação cliente-corretora, a existência de instituições como a CVM e a Bovespa parece sugerir que a predisposição à confiança irá efetivamente influenciar positivamente a percepção de segurança do ambiente pelo investidor. Isso parece indicar que investidores podem estar avaliando positivamente a segurança dos ambientes online de home brokers baseados em sua predisposição para confiar na corretora como um todo e nas instituiçóes reguladoras de suas operaçôes, estando em linha com o que se argumenta na literatura (BARBER, ODEAN, 2000; SHAPIRO, 1987). Sendo assim, em um ambiente normatizado em que as instituiçóes reguladoras são fortes e confiáveis, elas desempenham um papel importante no processo de formação da confiança do consumidor.

A hipótese 3, de que a segurança percebida teria efeito direto e positivo sobre a competência operacional percebida, foi verificada ( $p$-value < 0,001 ), indicando que, na mente do investidor, aspectos ligados à segurança desempenham papel de grande importância na formação da percepção da competência operacional da corretora online (o coeficiente padronizado para tal relaçáo foi de 0,87$)$. No caso brasileiro, como a CVM atua de forma rígida com relação ao monitoramento do mercado, emitindo normas e diretrizes de como as corretoras devem atuar em termos operacionais com relação à capacidade dos sistemas, escalas, planejamento de contingência (em caso de falha dos sistemas), oportunidade de negócios, qualidade das informaçóes prestadas, fóruns de discussão online e privacidade, isso parece afetar de forma positiva essa percepção, fazendo que o investidor perceba uma competência operacional das corretoras, uma vez que elas estão sob normas da CVM e da Bovespa.

A percepção de segurança também afeta significativamente a confiança, conforme sugerido pela hipótese 4 ( $p$-value $=0,005)$. Esse resultado pode ser interpretado como indicativo de que os usuários, ao perceberem um serviço de home broker como seguro, tendem a confiar mais nele e em sua competência operacional (coeficiente padronizado de 0,54), o que faz sentido em transações financeiras. Isso é importante para, indiretamente, afetar positivamente a satisfação do indivíduo via confiança. Conforme já apontado por Geffen (2000) e Yoon (2002), em transações online, a confiança é fator crucial para que ocorram transaçóes, particularmente, em ambiente de serviços financeiros (HARRISON, 2003). Dessa forma, o resultado aqui encontrado está em linha com a literatura, indicando que a percepção de segurança desempenha importante papel na construção da confiança, fator esse que irá afetar positivamente a satisfação final do indivíduo com a corretora durante o relacionamento entre ambas as partes.

A hipótese 5 (verificada $-p$-value $=0,023)$ propóe que a competência operacional percebida afeta direta e positivamente a confiança. Isso revela que há certa influência da competência operacional percebida pelos investidores na confiança por eles depositada nos serviços de uma corretora online (coeficiente padronizado de 0,48 ). Fatores levados em consideração na definição da competência operacional dos serviços oferecidos como tempo de execução das transaçóes e os preços a elas relacionados, qualidade dos resultados das pesquisas e assistência de qualidade/presteza do atendimento são importantes para influenciar positivamente a confiança do investidor, 
confirmando o argumento de Shih-Ming, Hsiu-Li e Hui-Min (2012) de que a decisão em continuar com a intenção de usar os serviços financeiros online é ligada diretamente a confiança depositada no provedor de serviços, e essa é construída por meio da competência operacional do provedor. $\mathrm{Na}$ presença desses fatores, a confiança na corretora tende a aumentar ao longo do relacionamento.

Assim, da mesma forma que a percepção de segurança afeta a confiança, uma competência operacional percebida positiva ajuda na construção da confiança em relacionamentos de longo prazo, como no caso da relação com corretoras online, o que indiretamente irá também afetar de forma positiva a satisfação do indivíduo. Ou seja, ambos os fatores são importantes para a construção da confiança e de forma indireta influenciam a satisfação final do indivíduo durante o relacionamento com a corretora.

Já a hipótese 6 apresentou efeito direto e positivo da confiança do investidor sobre a satisfação $(p$-value $<0,001)$, indicando uma forte relação (coeficiente padronizado de 0,89 ), reforçando o argumento da literatura de que em ambientes virtuais a confiança precede a satisfação (CHIOU, PAM, 2009; PO-HUNG, 2013; SIU, ZHANG, LAM, 2010). Os resultados aqui encontrados mostram os fatores que levam à construção da satisfação em relacionamentos de longo prazo no ambiente dos home brokers. Sobre a importância crucial da confiança em ambientes online, mostrou-se como as dimensóes que afetam diretamente sua formação, como a percepção de segurança e a competência operacional percebida positiva, ajudam também na em relacionamentos de longo prazo, como no caso da relação com corretoras online, o que indiretamente irá também afetar de forma positiva a satisfação do indivíduo (efeito indireto de magnitude de 0,846 da segurança na satisfação e de 0,423 da competência operacional sobre a satisfação). Ou seja, ambos os fatores são importantes para a construção da confiança e de forma indireta influenciam a satisfação final do indivíduo durante o relacionamento com a corretora. Evidenciou-se também como a confiança é importante para que o indivíduo venha a ter uma satisfação positiva quando confia na corretora.
Dessa forma, açóes devem ser prioritariamente na direção da formação e consolidação da confiança do investidor, pois se verifica que a confiança depositada pelos investidores em serviços de home broker oferecidos por corretoras de valores online têm uma forte influência sobre sua satisfação com os serviços recebidos. Ressalta-se que em serviços de trocas relacionais o fator confiança é crucial para construção da longevidade de relacionamento (GARBARINO, JOHNSON, 1999). Portanto, essas açôes devem ser claramente comunicadas aos usuários com o intuito de aumentar a sensação de confiança quando eles estiverem transacionando com as corretoras.

Por fim, não foi verificada a hipótese 1 . Ao se considerar o impacto da disposição para confiança sobre a competência operacional percebida, verificou-se que tal efeito não foi significativo $(p$-value $=0,135)$, levando-a a ser rejeitada. A disposição para confiança não apresentou efeito significativo sobre a percepção de competência no contexto de corretagem online pesquisado. Uma possível explicação para esses resultados, que contradiz pesquisas anteriores (BALASUBRAMANIAN, KONANA, MENON, 2003), pode estar ligada ao fato de que, no contexto brasileiro, a percepção da competência operacional, no que diz respeito aos serviços de home broker, não depende da disposição para a confiança que seus clientes tenham nela. Como o ambiente brasileiro, no que diz respeito às corretoras de valores, já é relativamente consolidado em regras e instituiçôes confiáveis, não é necessariamente relevante a existência de uma predisposição para confiar, no sentido de isso afetar a percepção da competência operacional que o indivíduo possa vir a ter. Ou seja, a percepção de uma competência operacional não depende dessa predisposição do indivíduo. Nesse sentido, pode-se investigar que outros fatores venham a influenciar positivamente o indivíduo, como fatores ligados aos aspectos técnicos no ambiente virtual e como eles poderiam influenciar na percepção do indivíduo durante o relacionamento.

Em suma, os resultados do modelo utilizado estabelecem efeitos diretos, positivos e significativos entre os construtos para todas as 
hipóteses testadas, e efeitos indiretos na formação da satisfação, com exceção para primeira hipótese (H1). A magnitude dos efeitos foi, na maioria dos casos, superior a 0,50 (exceto para o efeito de predisposição à confiança sobre segurança percebida, que foi de 0,20, e da relação Competência $\rightarrow$ Confiança, mas que chegou próximo a 0,50 , atingindo 0,48$)$, sendo os dois efeitos mais fortes observados na relação entre segurança percebida e competência operacional percebida $(0,87)$ e na relação entre confiança e satisfação $(0,89)$.

\section{CONCLUSÓES}

Este estudo contribui para aumentar a compreensão do comportamento do indivíduo em repetidas transaçôes no ambiente virtual em serviços financeiros, particularmente a respeito de serviços de home broker. Usando o contexto nacional como palco de investigação, buscou-se avaliar a satisfação do investidor nesse ambiente e como a formação da confiança dos investidores em serviços de corretagem online é elemento crucial para afetar de forma positiva essa satisfação. Os resultados da pesquisa indicaram que foi possível identificar fatores relevantes que influenciam a confiança e como essa afeta a satisfação do consumidor desse tipo de serviço. A contribuição teórica deste trabalho reforça uma corrente da literatura que indica que a confiança precede a satisfação no ambiente virtual (CHIOU, PAM, 2009; PO-HUNG, 2013; SIU, ZHANG, LAM, 2010), em contrapartida a autores que sugerem que a satisfação precede a confiança (TALEGHANI, CHOOBEH, MOUSAVIAN, 2011).

Os resultados e as relaçóes apresentados, entretanto, revelam outras contribuiçôes relevantes para a compreensão do contexto brasileiro de serviços de home broker, pois evidenciam alguns aspectos do comportamento do consumidor brasileiro consistentes com consumidores de outras nacionalidades. Primeiramente, confirma-se a importância do uso de construtos cognitivos no estudo do comportamento do consumidor e da relevância desses construtos para a compreensão do consumo de serviços online. Conforme já apontaram Johnson e Grayson (2005), a percepção de competência e a percepção da confiabilidade de um prestador de serviços, aspectos associados à confiança cognitiva, desempenham importante papel na formação da confiança.

Segundo, verificou-se também a forte influência dos construtos segurança percebida (com efeito indireto de magnitude de 0,846) e da confiança sobre a satisfação de clientes em ambientes online, sobretudo no caso de serviços de home broker. Os efeitos desses construtos sobre a satisfação já haviam sido identificados por Balasubramanian, Konana e Menon (2003), mas o impacto desses mesmos construtos no cenário de serviços online brasileiro ainda não havia sido verificado. Foi possível identificar que a segurança percebida e a confiança depositada em uma empresa que oferece serviços online impactam fortemente na satisfação do cliente com os serviços oferecidos.

Terceiro, a utilização de um construto pouco investigado na literatura, como o construto predisposição à confiança, também aumenta a compreensão da formação da confiança e da satisfação do consumidor. A princípio, a predisposição à confiança afeta ligeiramente a percepção de segurança. Por seu lado, essa segurança percebida parece agir de maneira forte e direta sobre a competência operacional percebida e a confiança, e também exercer forte influência indireta sobre a satisfação, por meio de sua ação sobre esses dois construtos. Por fim, foi visto também que a competência operacional percebida sofre forte influência da segurança percebida e exerce alguma influência direta sobre a confiança, que exerce influência forte e direta sobre a satisfação do consumidor com serviços financeiros online. Em suma, os resultados aqui apresentados contribuem de certa forma para aumentar a compreensão na formação da confiança do consumidor em serviços financeiros em ambientes virtuais, reforçando a ideia de que no ambiente virtual a confiança preceder a satisfação.

\section{I Implicaçóes gerenciais}

No que diz respeito a implicaçôes gerenciais, este artigo apresenta alguns insights que 
podem ser úteis para empresas que forneçam serviços no âmbito online, particularmente empresas de corretagem. A satisfaçáo do cliente e os relacionamentos de negócios em ambientes virtuais podem ser mais bem gerenciados quando questōes de competência e confiança são trabalhadas simultaneamente. Os resultados obtidos suportam essa visão com confiança e segurança, sendo duas variáveis de grande importância para a satisfação do cliente de home broker no Brasil. Isso indica que é importante que os provedores de serviços financeiros busquem oferecer respostas rápidas de processos, informações confiáveis e fáceis de serem obtidas e facilidade de navegação em suas páginas, bem como invistam em aspectos que aumentem a segurança da operação, melhorando a percepçáo que o indivíduo venha a ter ao fazer uma transação no site. Gerentes devem focar esforços em clarificar os dispositivos de segurança utilizados nas operaçôes de suas empresas, assim como trabalhar de forma que possam criar uma percepção de segurança no indivíduo, explicitando como as regulamentaçóes e regras impactam positivamente sobre suas operaçôes. Além disso, um ambiente otimizado, rápido e de qualidade irá influenciar positivamente a competência operacional percebida e a confiança depositada, afetando consequentemente a satisfação do cliente.

\subsection{Limitaçóes e pesquisas futuras}

Uma das limitaçóes do estudo diz respeito à coleta e ao tratamento dos dados. Em relação à validade externa dos resultados, dada a amostra de conveniência e o fato de que os dados refletem somente a visáo de usuários de serviço de home broker de algumas corretoras do Brasil, é possível que as relações verificadas na pesquisa não sejam generalizáveis para todo e qualquer tipo de consumidor de serviços dessa natureza.

Com relação a pesquisas futuras, a replicação do modelo testado junto a um número maior de consumidores com perfis diferentes dos estudados neste trabalho e com outros serviços oferecidos em ambiente virtuais seria uma boa forma de validar e ampliar o escopo dos resultados aqui obtidos. Pesquisas futuras podem explorar também outras escalas para os construtos utilizados no modelo ou construtos conceitualmente similares, comparando seus resultados com os obtidos aqui. Por fim, seria interessante a investigação de possíveis efeitos moderadores que algumas variáveis demográficas (como sexo, renda e idade) poderiam apresentar sobre as relaçôes observadas.

Por fim, deve-se investigar por que a hipótese 1 não foi confirmada, contradizendo estudos anteriores. Há que se buscar quais fatores efetivamente influenciam uma percepçáo de competência operacional por parte do usuário ao efetuar transações online.

\section{REFERÊNCIAS}

ANDERSEN, C. E. Home Broker: como investir em açôes pela internet. Rio de Janeiro: Editora Ciência Moderna, 2006.

BALASUBRAMANIAN, S.; KONANA, P.; MENON, N. M. Customer satisfaction in virtual environments: a study of online investing. Management Science, Linthicum, v. 49, n. 7 , p. 871-889, July 2003.

BARBER, B. M.; ODEAN, T. Trading is hazardous to your wealth: the common stock investment performance of individual investors. Journal of Finance, Malden, v. 55, n. 2, p. 773-806, Apr. 2000.

BYRNE, B. M. Structural equation modeling with amos: basic concepts, applications and programming. 2nd ed. Routledge: New York, 2010.

CASALO, L.V.; FLAVIAN, C.; GUINALIU, M. The influence of satisfaction, perceived reputation and trust on a consumer's commitment to a website. Journal of Marketing Communications, London, v.13, n.1, p. 1-17, 2007.

CHIOU, J.; PAN, L. Antecedents of internet retailing loyalty: differences between heavy versus light shoppers. Journal Of Business \& Psychology, [S. 1.], v. 24, n. 3, p. 327-339, Sept. 2009. 
CHIUNG-JU, L.; HUI-JU, C. A study of the impacts of website quality on customer relationship performance. Total Quality Management \& Business Excellence, [S. 1.], v. 20, n. 9, p. 971-988, 2009.

COMISSÃO DE VALORES MOBILIÁRIOS (CVM). Negociaçóes “on line”. [20--]. Disponível em: <http://www.cvm.gov.br/port/protinv/ caderno5.asp>. Acesso em: 22 out. 2009.

FORNELL, C.; LARCKER, D. F. Evaluating structural equation models with unobservable variables and measurement error. Journal of Marketing Research, [S. 1.], v. 18, n. 1, p. 3950. Feb. 1981

GARBARINO, E.; JOHNSON, M. S. The different roles of satisfaction, trust, and commitment in customer relationships. Journal of Marketing, London, v. 63, n. 2, p. 70-87, Apr. 1999.

GEFEN, D. E-commerce: the role of familiarity and trust. Omega, [S. 1.], v. 28, n. 6, p. 725-737, Dec. 2000.

GEYSKENS, I.; STEENKAMP, J. E. M.; KUMAR, N. Generalizations about trust in marketing channel relationships using meta-analysis. International Journal of Research in Marketing, Amsterdam, v. 15, n. 3, p. 223-48, July 1998.

A meta-analysis of satisfaction in marketing channel relationships, Journal of Marketing Research, Amsterdam, v.36, n. 2, p. 223-238, May 1999.

GIFFEN, K. The contribution of studies of source credibility to a theory of interpersonal trust in the communications process. Psychology Bulletin, Thousand Oaks, v. 68, n. 2, p. 104-120, Agu. 1967.

GULATI, R.; NOHRIA, N.; ZAHEER, A. Strategic networks. Strategic Management Journal, Chichester, v. 21, n. 3, p. 203-215, 2000.

HAIR, J. F. et al. Multivariate data analysis. 7. ed. Upper Saddle River: Prentice-Hall, 2009.
HARRIS, L. C.; GOODE, M. H. The four levels of loyalty and the pivotal role of trust: a study of online service dynamics. Journal of Retailing, New York, v. 80, n. 2, p. 139-58, 2004.

HARRISON, T. Why trust is important in customer relationships and how to achieve it. Journal of Financial Services Marketing, London, v. 7 , n. 3, p. 206-209, Mar.2003.

HU, L.; BENTLER, P. M. Cutoff criteria for fit indexes in covariance structure analysis: Conventional criteria versus new alternatives. Structural Equation Modeling, Philadelphia, v. 6, n. 1, p. 1-55, 1999.

JOHNSON, D. S.; BARDHI, F.; DUNN, D. T. Understanding how technology paradoxes affect customer satisfaction with self-service technology: the role of performance ambiguity and trust in technology. Psychology \& Marketing, [S. 1.], v. 25, n.5, p. 416-443, May 2008.

JOHNSON. D.; GRAYSON, K. Cognitive and affective trust in service relationships. Journal of Business Research, New York, v. 58, n. 4, p. 500-507, Apr. 2005.

KIM, C. et al. An empirical study of customers' perceptions of security and trust in e-payment systems. Electronic Commerce Research and Applications, [S. 1.], v. 9, n. 1, p. 84-95. Jan./ Feb. 2010 .

KIM, M. J.; CHUNG, N.; LEE, C. K. The effect of perceived trust on electronic commerce: shopping online for tourism products and services in South Korea. Oxford, v. 32, n. 2, p 256-265, Apr. 2011.

KONANA, P.; MENON, N. M.; BALASUBRAMANIAN, S. The implications of online investing. Communications of the ACM, New York, v. 43, n. 1, p. 34-41, Jan.2000.

LIANG, C.; WANG, W. Integrative research into the financial services industry in Taiwan: Relationship bonding tactics, relationship quality and behavioural loyalty. Journal of Financial Services Marketing, v.10, n.1, p. 65-83, 2005. 
LORD, C.; LEPPER, M. R.; ROSS, L. Biased assimilation and attitude polarization: the effects of prior theories on subsequently considered evidence. Journal of Personality and Social Psychology, Washington, v. 37, n. 11, p. 20982109, Nov. 1979.

MCKNIGHT, D. H.; CUMMINGS, N. L., CHERVANY, N. L. Initial trust formation in new organizational relationships. Academy of Management Review, Briarcliff Manor, v. 23, n. 3, p. 473-490, July 1998.

MOORMAN, C.; DESHPANDE, R.; ZALTMAN, G. Factors affecting trust in market research relationships. Journal of Marketing, Chicago, v. 57, n. 1, p. 81-101, Jan. 1993.

MORGAN, R. M.; HUNT, S. D. The commitment-trust theory of relationship marketing. Journal of Marketing, Chicago, v. 58, n. 3, p. 20-38, July 1994.

MORROW, J. L.; HANSEN, M. H.; PEARSON A. W. The cognitive and affective antecedents of general trust within cooperative organizations. Journal of Managerial Issues, Pittsburgh, v. 16, n.1, p. 48-64, Spring 2004.

OLIVER, R. L. A cognitive model of the antecedents and consequences of satisfaction decisions. Journal of Marketing Research, Amsterdam, v. 17, n. 4, p. 460-469, Nov. 1980.

PARASURAMAN, A.; ZEITHAML, V. A.; BERRY, L. L. SERVQUAL: a multiple-item scale for measuring customer perceptions of service quality. Journal of Retailing, New York, v. 64, n. 1, p. 12-40, 1988.

; GREWAL, D. e KRISHNAN, R. Marketing research. 2nd ed. South-Western College Pub, 2006.

PEPPERS, D.; ROGERS, M. Managing customer relationships: a strategic framework. Hoboken: Wiley, 6th Edition, 2010.

PODSAKOFF, P. M.; ORGAN, D. W. Selfreports in organizational research: problems and prospects. Journal of Management, Thousand Oaks, v. 12, n. 4, p. 531-544, 1986.

PO-HUNG, L. Shopping motivations on the internet: an empirical study of trust, satisfaction and loyalty. International Journal of Electronic Business Management, Ithaca, v. 11, n. 4, p. 238246, Dec. 2013.

PORTER, M. E. Competiçáo: estratégias competitivas essenciais. Rio de Janeiro: Campus, 1999.

ROMAN, S. The ethics of online retailing: a scale development and validation from the consumers' perspective. Journal Of Business Ethics, Dordrecht, v. 72, n. 2, p, 131-148, May 2007.

ROUSSEAU, D. M. et al. Not so different after all: a cross-discipline view of trust. Academy of Management Review, Briarcliff Manor, v. 23, n. 3, p. 393-404, 1998.

ROSSI, G. B. Preferences process formation in internet environment. São Paulo: Iberoamerican Academy of Management, 2003.

SANTOS, C. P.; FERNANDES, D. V. H. A recuperação de serviços como ferramenta de relacionamento e seu impacto na confiança e lealdade dos clientes. RAE: Revista de Administraçáo de Empresas, São Paulo, v. 48, n. 1, p. 10-24, jan./ mar. 2008.

SELNES, F. Antecedents and consequences of trust and satisfaction in buyer-seller relationships. European Journal of Marketing. [S. 1.], v. 32, n. 3/4, p. 305-322, 1998.

SEVERT, E. The customer's path to loyalty: a partial test of the relationships of prior experience, justice, and customer satisfaction. 2002. 118 f. Thesis (Doctor of Philosophy)Faculty of the Virginia Polytechnic Institute and State University, Blacksburg, 2002.

SHANKAR, V.; SMITH, A.; RANGASWAMY, A. Customer satisfaction and loyalty in online and offline environments, International Journal of Research in Marketing, Amsterdam, v. 20, n .2, p. 153-175, June 2003. 
SHAPIRO, S. P. The social control of impersonal trust. American Journal of Sociology, Chicago, v. 3 n, 3, p. 623-658, Nov. 1987.

SHIH-MING, P.; HSIU-LI, L.; \& HUI-MIN, C. Factors that affect consumers' trust and continuous adoption of online financial services. International Journal of Business \& Management, [S. 1.], v. 7, n. 9, p. 108-119, May 2012.

SINGH, J.; SIRDESHMUKH, D. Agency and trust mechanisms in relational exchanges. Journal of the Academy of Marketing Science, [S. 1.], v. 28 , n. 1 , p. $150-167$, Dec. 2000.

SIRDESHMUKH, D.; SINGH, J.; SABOL, B. Consumer trust, value, and loyalty in relational exchanges. Journal of Marketing, Chicago, v. 66, n. 1, p. 15-37, Jabn. 2002.

SIU, N. Y.; ZHANG. J.; LAM, Y. Electronic service quality and routes to site commitment: the case of an online film ticketing service. Journal of International Consumer Marketing, Binghamton, v.22, n.3, p. 293-307, 2010.

SMITH, B. J.; BARCLAY, D. W. The effects of organizational differences and trust on the effectiveness of selling partner relationships. Journal of Marketing, Chicago, v. 61, n. 1, p. 3-21, Jan. 1997.

TALEGHANI, M.; CHOOBEH, E.; MOUSAVIAN, S. The role of loyalty dimentions in customer orientation process for new enterprises in tourism industries of Iran. Australian Journal of Business \& Management Research, [S. 1.], v. 6, n. 1, p. 143-151, Sept. 2011.

TAM, J. M. Linking perceived service quality to relational outcomes in a chinese context. Journal of International Consumer Marketing, Binghamton, v. 24, n .1/2, p. 7-23, 2012.

TAYLOR, S. E.; BROWN, J. D. Illusion and well-being: a social psychology perspective on mental health. Psychology Bulletin, Washington, D.C, v. 103, n. 2, p. 193-210, Mar. 1988.

VENKATRAMAN, N.; HENDERSON, J. C. Real strategies for virtual organizing. Sloan Management Review, Cambridge, v. 40, n. 1, p. 33-48, Fall 1998.

WANG, Y. D.; EMURIAN, H. H. An overview of online trust: concepts, elements, and implications. Computers in Human Behavior, Oxford, v. 21, n. 1, p. 105-125, Jan. 2005.

YOON, S. J. The antecedents and consequences of trust in online-purchase decisions. Journal of Interactive Marketing, New York, v. 16, n. 2, p. 47-63, Spring 2002.

ZEITHAML, V. A.; PARASURAMAN, A.; MALHOTRA, A. A conceptual framework for understanding e-service quality: implications for future research and managerial practice. Reports, Marketing Science Institute, 2000.

\section{ANEXO A}

Tabela de correlaçóes e estatísticas descritivas dos construtos

\begin{tabular}{lccccccc} 
& Satisfaçáo & Confiança & Segurança & Competência & Disposiçáo & Média & Desvio \\
\hline Satisfaçáo & 1 & 0,675 & 0,735 & 0,613 & 0,149 & 4,4 & 1,31 \\
Confiança & 0,675 & 1 & 0,725 & 0,565 & 0,184 & 4,4 & 0,92 \\
Segurança & 0,735 & 0,725 & 1 & 0,612 & 0,135 & 4,4 & 0,92 \\
Competência & 0,613 & 0,565 & 0,612 & 1 & 0,257 & 4,6 & 0,77 \\
Disposiçáo & 0,149 & 0,184 & 0,135 & 0,257 & 1 & 4,2 & 0,86 \\
\hline
\end{tabular}

Nota: Todas as correlações foram significativas a um nível de 0,05. 